\title{
Spectroscopic Studies on Biodegradable Polymer Blend Having Antimicrobial Biological and Adsorbent Property used in Wastewater Treatment ${ }$
}

\author{
N. PRAKASH ${ }^{\mathrm{a}, \mathrm{d}}$, SRINIVASAN LATHA ${ }^{* \mathrm{~b}}$, P. N. SUDHA ${ }^{\mathrm{c}}$ and N. G. RENGANATHAN ${ }^{\mathrm{d}}$ \\ ${ }^{a}$ Department of Chemistry, Sri Chandrasekharendra Saraswathi Viswa Mahavidyalaya \\ (SCSVMV) University, Kancheepuram, India \\ ${ }^{b}$ Department of Chemistry, SRM University, Kattankulathur, India \\ ${ }^{\mathrm{c}}$ P. G. and Research Department of Chemistry, D.K.M. College for Women, Vellore, India \\ ${ }^{\mathrm{d}}$ Department of Chemistry, Veltech Dr. RR \& Dr. SR Technical University, \\ Chennai-62, India \\ latha.chinnu@gmail.com
}

Received 17 January 2013 / Accepted 15 February 2013

\begin{abstract}
Clean drinking water paves way to a healthy human race. The key solution to this problem is to develop an efficient and cost effective purifying technology using natural and modified adsorbents. Chitosan, a biodegradable polymer can be used as a stand alone membrane. Chitosan and nylon 6-synthetic polymer blend and chitosan and clay-natural polymer blend, have been attempted in the present study to regenerate water from industrial wastewater effluent. As adsorbent for the removal of heavy metals from water, biopolymers have been studied. In the present study, chitosan was blended with clay membrane and was used in removing copper and cadmium from synthetic industrial wastewater. Attentions was focused on the spectroscopic properties of chitosan-nylon 6, chitosan-clay membranes and were compared. This is to understand the various interactions of the groups in clay, which are not present in nylon 6. The polymer blends were synthesized and characterized using FT-IR, XRD and TGA/DTA. The results showed that the polymer blends possess antibacterial property in addition to being good adsorbents. Results are presented and discussed.
\end{abstract}

Keywords: Chitosan, Clay, Nylon 6, Antimicrobial activity

\section{Introduction}

Clean drinking water is the main issue to have a healthy human population. By extensive use of chemicals and due to rapid industrialization, water gets polluted. Problems in drinking water quality include the presence of excess fluoride, arsenic and natural organic matters, heavy metals and a variety of pathogens. Cost effective and efficient use of natural and modified adsorbents is the solution to this problem. Several natural adsorbents are being used for the treatment of contaminated drinking water and its sources. Chitosan which is a biodegradable polymer can be used as stand alone membrane or chitosan and nylon 6 , which

$†$ Presented to the National Conference on Chemistry Solutions at SRM University, India 
are synthetic polymer blend and chitosan and clay which are a natural polymer blend, have been attempted in the present study to regenerate water from wastewater effluent from the industries. Clay minerals are widely used because of their high specific surface area, chemical and mechanical stability, a variety of surface and structural properties and low $\operatorname{cost}^{1-4}$. Ion exchange methods like reverse osmosis process is usually followed not only in removing heavy metal ions but also for purification of water. Generally adsorption is the main underlying principle in these processes. Biosorption technique involves active and non active uptake by biomass and is a good alternative to the traditional processes. These processes seem to be not only eco friendly but also recyclable and hence attempts have been made in this work to synthesize bio degradable polymers which will be used to remove heavy metals. In the case of bio-polymers chitin, chitosan, clay and nylon 6 and glutaraldehyde are widely employed as bio polymers. Biopolymers have been studied as adsorbents for the removal of heavy metals from water. Chitosan is the one of them ${ }^{5,6}$. It has a better adsorption capacity for metal ions. It has severe limitations in its use in acidic media because of its solubility in $\operatorname{acid}^{7,8}$. In the present study chitosan is blended with clay membrane and is used in removing copper and cadmium from synthetic industrial wastewater.

\section{Experimental}

Chitosan (90\%) from DNP International (city and state) was used to make all chitosan solutions. Chitosan solutions from 2 to $20 \mathrm{~g} / \mathrm{L}$ were used for the experiments. The powdered chitosan was weighed and dissolved in $0.05 \mathrm{M}$ or $0.01 \mathrm{M}$ acetic acid depending on the $\mathrm{pH}$ required. Slight adjustments in $\mathrm{pH}$ were made using $1 \mathrm{M}$ acetic acid. Standard heavy metal stock solutions (1000 mg/L) was prepared by dissolving $200 \mathrm{mg} / \mathrm{L} \mathrm{CuCl}_{2}$, $200 \mathrm{mg} / \mathrm{L} \mathrm{CdCl} 2 . \mathrm{pH}$ adjustment of solutions were made using dilute or concentrated $\mathrm{NaOH}$ (Sigma Chemicals Co.) and $\mathrm{HCl}$ (Sigma Chemicals Co.) solutions using Orion $420 \mathrm{~A} \mathrm{pH}$ meter. All the reagents were of analytical grade and stored in polyethylene polypropylene containers.

\section{Preparation of nylon 6}

Nylon 6 in pellet form was obtained from DuPont and had a molecular weight of 19,000. Chitosan (92\% deacetylated) was obtained from India Sea Foods, Cochin.

\section{Preparation of clay}

The suspension of kaolin clay was prepared by mixing $1 \mathrm{~g}$ of clay in $25 \mathrm{~mL}$ of de-ionized water and stirring in moderate speed for $20 \mathrm{~min}$.

\section{Anti microbial activity}

The assay was carried out by well diffusion method. Muller Hinton Agar plates (Bacteria) and Potato Dextrose Agar (Fungi) were spread with respective culture using a swab and wells are bored in each plate at the diameter of $6 \mathrm{~mm}$ each. The wells were filled with polymer blends [(chitosan/nylon 6(1:1); chitosan/clay (1:1)] at the of concentration of (25 $\mu \mathrm{g} /$ well respectively). The bacterial plates were incubated at $37{ }^{\circ} \mathrm{C}$ for $24 \mathrm{~h}$ and the plates holding fungal cultures were incubated at $28{ }^{\circ} \mathrm{C}$ for $72 \mathrm{~h}$. The zone of inhibition (ZOI) was measured by subtracting the well diameter from the total inhibition zone diameter. Chloramphenicol (30 $\mu \mathrm{g} / \mathrm{disc})$ and Amphotericin B (100 unit/well) used as positive control for bacterial and fungal species, the assays were performed in triplicate. 


\section{Results and Discussion}

\section{FTIR spectra analysis}

Figure 1 compares the FT-IR spectrum of chitosan and chitosan and nylon 6 (1:1). As per ${ }^{9}$ the peak at $1628 \mathrm{~cm}^{-1}$ has been assigned to water. But the peak at $1087 \mathrm{~cm}^{-1}$ may be due to $\mathrm{C}-\mathrm{O}-\mathrm{C}$ stretching in the spectrum of pure chitosan. According to ${ }^{10}$ the amide group band of chitosan will appear at 1628 to $1650 \mathrm{~cm}^{-1}$. The shift of the bands in these areas is attributed to the molecular miscibility of the polymers On the contrary inter hydrogen bonds are formed between chitosan and nylon 6. For pure chitosan and nylon 6 the displacement number was about $25 \mathrm{~cm}^{-1}$ (from 1650 to $1628 \mathrm{~cm}^{-1}$ ). This may be due to the chelation effect caused by the coordination interaction between $\mathrm{NH}_{2}$ groups of the chitosan and nylon $6^{11}$.

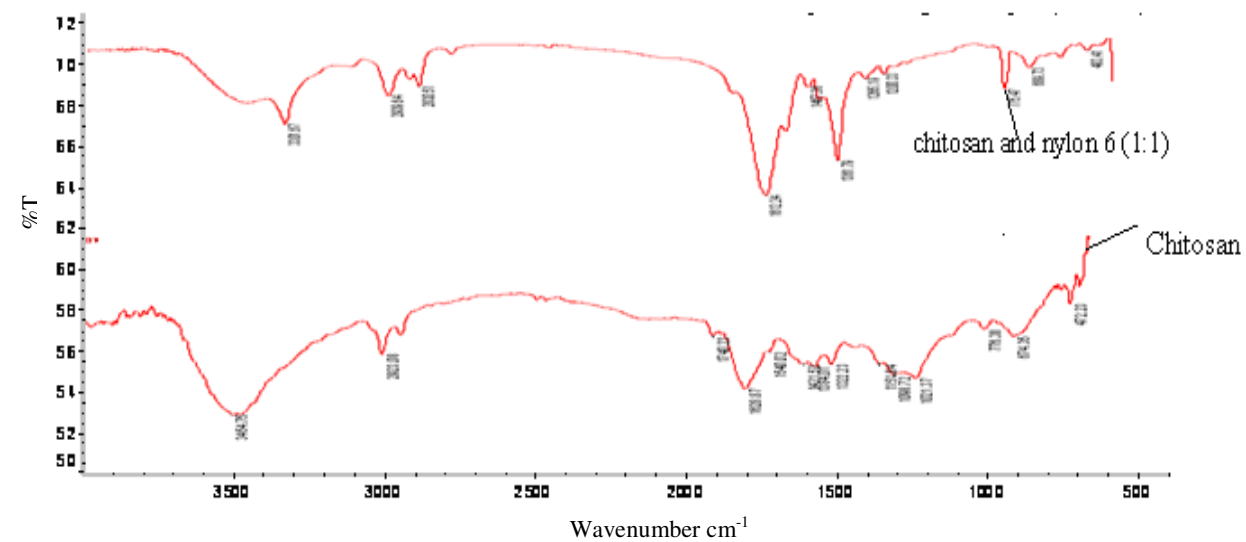

Figure 1. FT-IR spectrum of chitosan, nylon 6 (1:1)

Figure 2 shows the FT-IR spectrum of chitosan and clay. The main vibration bands in this spectrum are at $3622 \mathrm{~cm}^{-1}$ (for $\mathrm{O}-\mathrm{H}$ stretching) at $3428 \mathrm{~cm}^{-1}$ (due to interlay red $\mathrm{O}-\mathrm{H}$ stretching) $\mathrm{H}$ - bonding at $1635 \mathrm{~cm}^{-1}$ (for $\mathrm{H}-\mathrm{O}-\mathrm{H}$ bending) $957 \mathrm{~cm}^{-1}$ and $845 \mathrm{~cm}^{-1}$ (for Si-O stretching) at $542 \mathrm{~cm}^{-1}$ (for Si-OH stretching peaks ${ }^{12}$ and $520 \mathrm{~cm}^{-1}$ and $430 \mathrm{~cm}^{-1}$. The peaks of $-\mathrm{NH}_{2}$ groups in pure chitosan at 1643 and $1578 \mathrm{~cm}^{-1}$ are shifted to $1635 \mathrm{~cm}^{-1}$ in the chitosan and clay, corresponding to the deformation vibration of amine group of chitosan ${ }^{13}$.

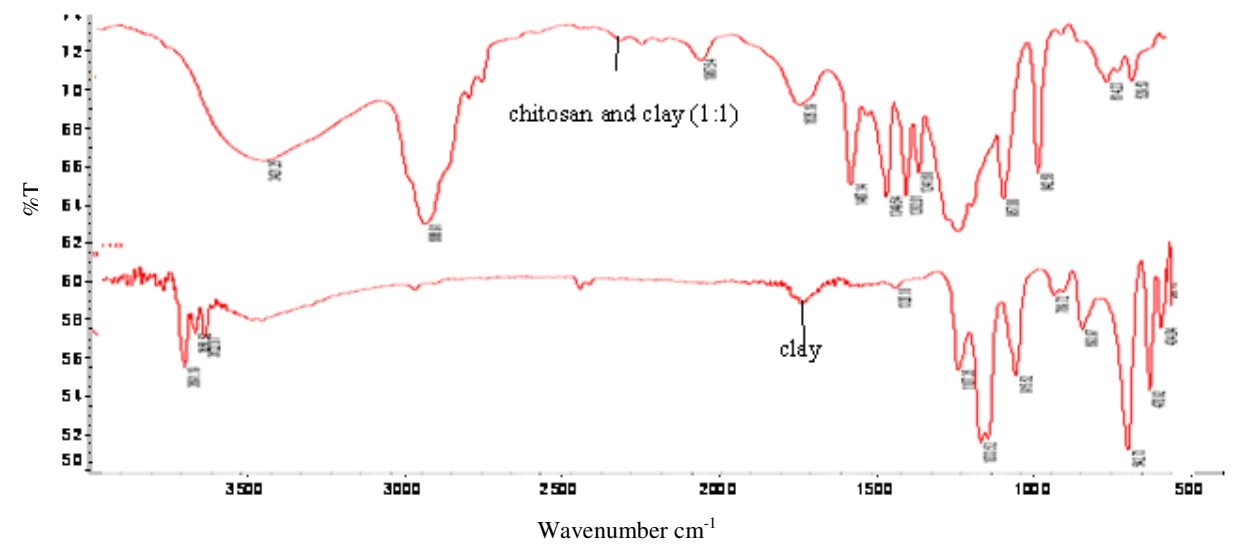

Figure 2. FT-IR spectrum of chitosan, clay $(1: 1)$ 
The peak at $915 \mathrm{~cm}^{-1}$ may be due to Si-O stretching and the peak at 542 and $470 \mathrm{~cm}^{-1}$ may be due to Si-O bending. The peak at $3622 \mathrm{~cm}^{-1}$ is missing in this figure and the $\mathrm{O}-\mathrm{H}$ stretching would not have been there since this would have been due to complexation of clay with chitosan. At $1635 \mathrm{~cm}^{-1}$ there is a peak which may be due to $\mathrm{H}-\mathrm{O}-\mathrm{H}$ bending. This may also be due to the overlapping of $\mathrm{H}-\mathrm{O}-\mathrm{H}$ bending peak with $\mathrm{N}-\mathrm{H}$ bending peak. This might have resulted as a deformation vibration peak of amine of chitosan. The peak at $1633 \mathrm{~cm}^{-1}$ is due to H-O-H bending vibrations. This may also be due to deformation peak of amine of chitosan with clay. Disappearance of peaks at $1368 \mathrm{~cm}^{-1}$ and $1308 \mathrm{~cm}^{-1}$ for clay and chitosan and existence of peak at $1382 \mathrm{~cm}^{-1}$ may be due to complexation between the amino groups of chitosan and clay. The peak at $1628 \mathrm{~cm}^{-1}$ indicates the complexation between the amino groups of chitosan and clay. As already discussed this peak may also be due to deformation and vibration of amine of chitosan.

\section{$X$-Ray diffraction analysis (XRD)}

Figure 3 shows the XRD data of pure nylon 6 . As it is, it gives the information that the state is amorphous and there is sharpness at two places. They are at 19.690 and 440 . A pure chitosan film shows four main diffraction peaks These confirm the presence of more polymer domains in its structure. This is in good agreement with the results reported by ${ }^{14}$. The diffractograms of pure chitosan and blend indicate that the materials are amorphous. From the diffractograms of pure chitosan and blend with nylon $6(1: 1)$ of chitosan indicate the presence of chitosan in general and miscibility of the polymer with blended polymer in particular. In general, the diffractogram containing $1: 1$, is similar to pure chitosan and this suggests that the polymers are miscible. This is understandable from the fact that the presence of hydrogen bonding via residual water molecules forms the blend and this is in agreement with ${ }^{15}$. In this residual water, the molecules will act as an active compatablizer in the blend.

IR spectroscopy may be an appropriate technique to study the biopolymer clay interaction, since a shift in the $\mathrm{NH}_{3}$ vibration has been reported when chelating transition metal ions by chitosan takes place. A similar behavior may also be expected when $-\mathrm{NH}_{3}+$ groups interact electrostatically with the negatively charged sites of the clay. In fact, a shift of the $\mathrm{NH}_{3}$ band towards a lower frequency is observed in all the chitosan montmorillonite nanocomposites Figure 3. Besides, the intensity of the $\mathrm{NH}_{3}$ band also increases for higher amounts of chitosan. The amide I band at $1650 \mathrm{~cm}^{-1}$ of chitosan is overlapped with the H-O-H bending vibration band at $1640 \mathrm{~cm}^{-1}$ of the water molecules associated to the nanocomposites, which are present in a similar amount than in the starting clay, as expected for a biopolymer with high water retention capability.

\section{Thermo gravimetric analysis (TGA)}

The second thermal event for pure chitosan and blend with nylon 6 is observed at about $300{ }^{\circ} \mathrm{C}$ with the maximal rate at $355-356{ }^{\circ} \mathrm{C}$ and is related to degradation, which includes the parallel processes of dehydration and demethoxylation. The degradation profile of chitosan is in good agreement with similar results reports ${ }^{16}$. The degradation profile of the blends containing 1:1 consists of the events typical for both chitosan and nylon 6 . This behavior could be observed for degradation of mechanical mixtures of the polymers and indicate on their miscibility in the blend. However, the degradation of the blend containing of chitosan shows only events characteristic for pure cellulose ether. The absence of the event typical for pure chitosan at $250-350{ }^{\circ} \mathrm{C}$ in this blend indicates on some interactions between the polymers and may be considered as a proof of their partial miscibility. 


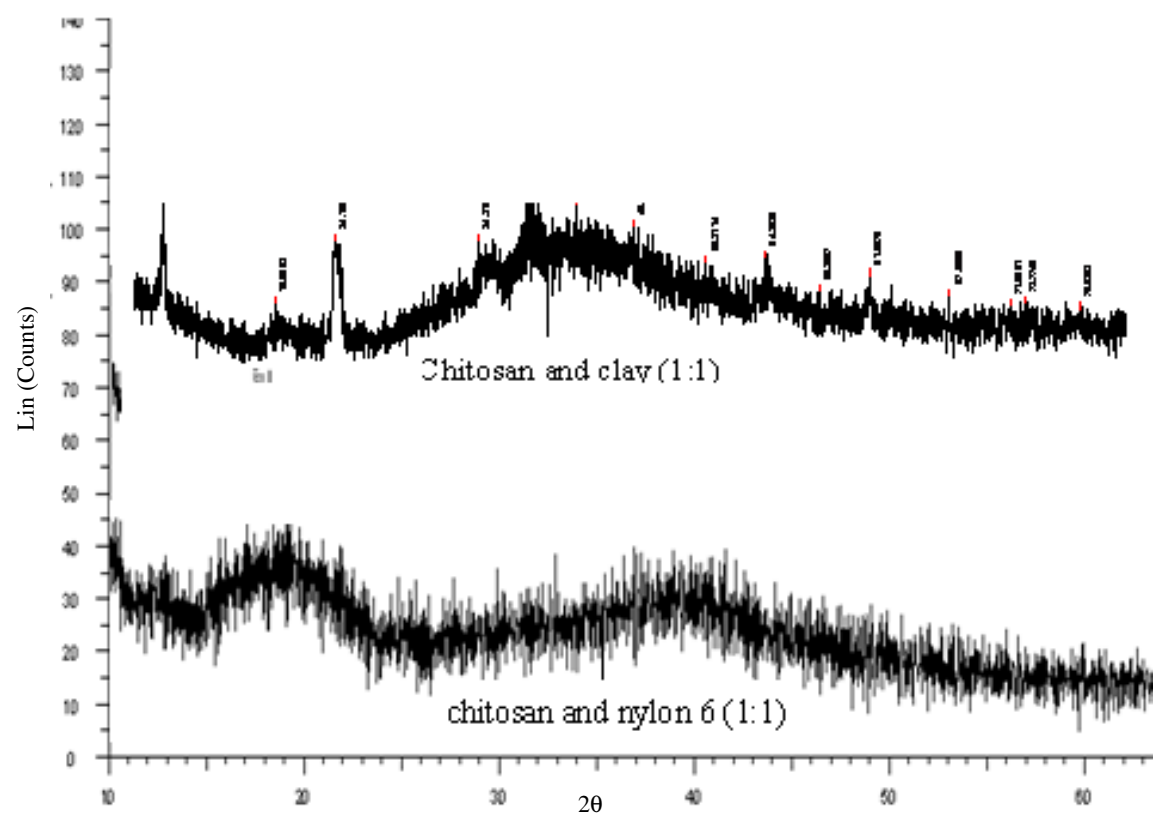

Figure 3. XRD pattern of chitosan, nylon 6 and clay $(1: 1)$

Thermogravimetric data of chitosan with clay particles are shown in Figure 4. All chitosan films were degraded at $286-297{ }^{\circ} \mathrm{C}$. This agrees very well with the results reported by ${ }^{17,10}$. The increase in the degradation temperature is generally regarded as a consequence of the low permeability of the clay like materials preventing oxygen to reach the polymer, and preventing the volatiles generated during the decomposition of the polymer to leave the clay.

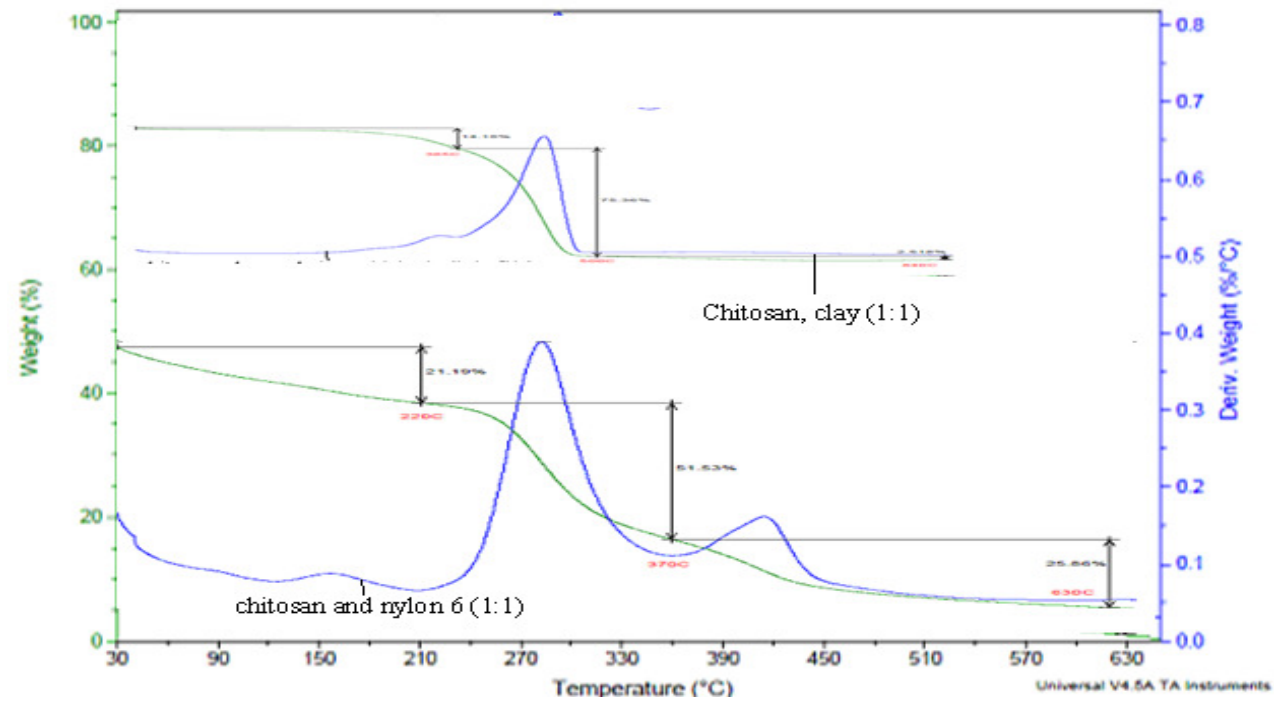

Figure 4. TG/DTG of chitosan, clay, nylon 6 (1:1) 


\section{Differential scanning calorimetry (DSC)}

Figure 5 shows the thermal properties of the chitosan, nylon 6 blended membranes. Glass transition temperatures $(\mathrm{Tg})$ were not observed both for chitosan and nylon 6. A broad endothermic was observed around $60{ }^{\circ} \mathrm{C}$ for the chitosan, nylon 6 membrane, which is an endothermic peak that exists for most polysaccharides at low moisture contents ${ }^{10}$. In the nylon 6 curve, a melting endothermic peak was observed at $225{ }^{\circ} \mathrm{C}$, which was associated with the crystalline polymer fraction. The characteristic peak of chitosan at about $60{ }^{\circ} \mathrm{C}$ became smaller with increasing nylon 6 content and the melting peak of nylon 6 at $230{ }^{\circ} \mathrm{C}$ became smaller with decreasing the nylon 6 content, but no obvious change in the melting temperature was observed ${ }^{18}$. This indicated that the nylon 6 crystallization decreased after blending with chitosan, and there was interaction between chitosan and nylon 6 .

From Figure 5, it is seen that differential scanning calorimetric data can be obtained for (1:1), however no meaningful DSC data could be obtained. This may be due to melting or thermal event that could have been delayed unlike in the other two cases. The first endothermic peak that occurs in the temperature range of $265.13{ }^{\circ} \mathrm{C}$ may be attributed to solvent evaporation ${ }^{10}$. The peak in the range of 230 to $520{ }^{\circ} \mathrm{C}$ indicates crystallization of the chitosan. This process is not inhibited by clay particles, this is evident from the appearance of the peak and there is no shift in the peak position as the content of clay is increased.

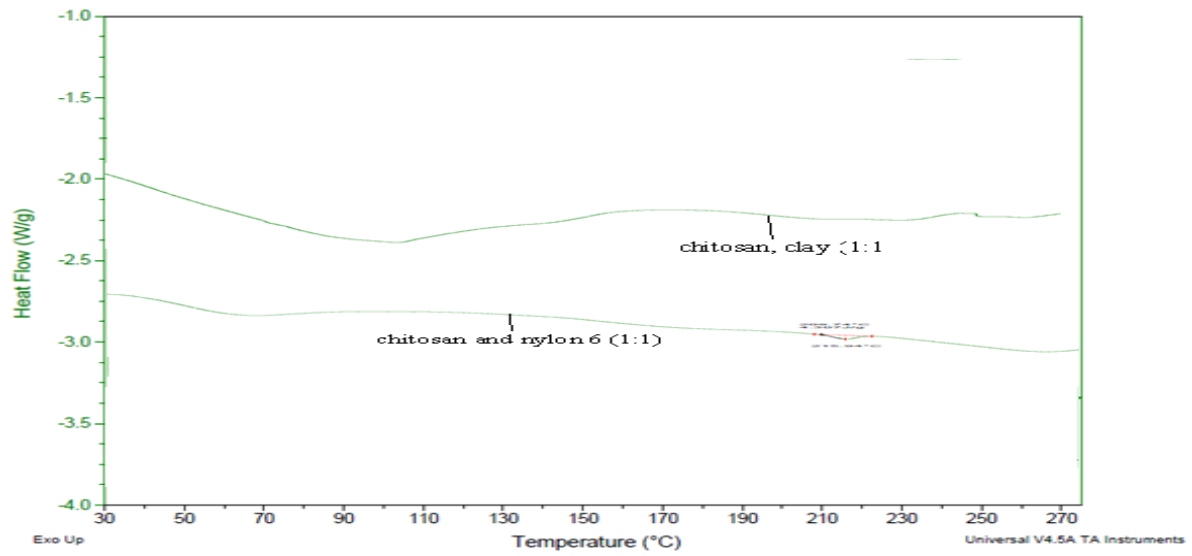

Figure 5. DSC of Chitosan, clay, nylon 6 (1:1)

\section{Antimicrobial activities}

Figure 6 and Figure 7 show anitimicrobial activity of chitosan and nylon 6 and chitosan and clay. Chitosan has been studied in terms of bacteriostatic/bactericidal activity to control the growth of chloramphenicol and to inhibit viral multiplication ${ }^{19}$. Moreover, towards mammalian cells chitosan, nylon 6 and clay possess antimicrobial activity. This is because they have higher killing rate and lower toxicity towards these cells. The blend with low content of chitosan has less antibacterial effect for all bacteria under test. At the same time, the antimicrobial activity of the blended composition increases with increasing the content of chitosan in the polymer blends. This phenomenon may be related to the presence of a lot amount of net positively charge in the chitosan macromolecules. But this is less pronounced in the case of blend with synthetic polymer viz., nylon 6 where there is less porous nature ${ }^{20}$. The same is more pronounced in the case of blend with natural polymer, viz., clay where there is more porous compared to nylon 6 . 


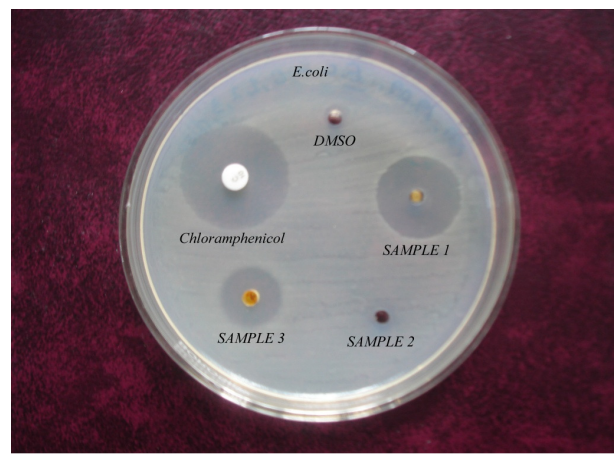

Figure 6. Antibacterial activity of chitosan/nylon $6(1: 1)$

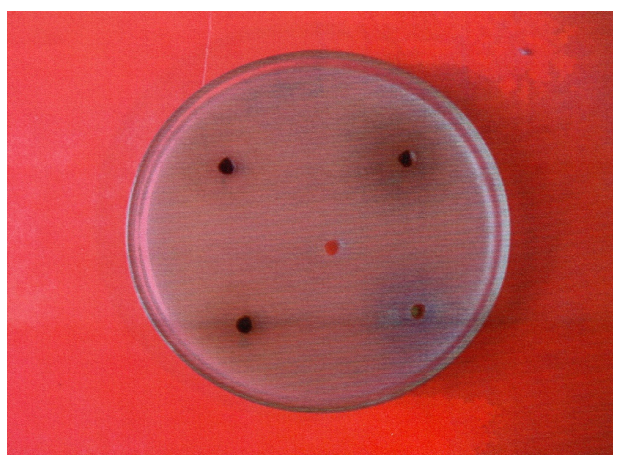

Figure 7. Antibacterial activity of chitosan/ clay $(1: 1)$

\section{References}

1. Prakash N, Srinivasan Latha, Sudha P N and Renganathan N G, Environ Sci Pollut Res., 2012, DOI:10.1007/s11356-012-0935-8.

2. $\quad$ Lin S H and Juang R S, J Hazard Mater B, 2002, 92(3), 315-326.

3. Krishna B S, Murty D S R and Jai Prakash B S, J Colloid Interface Sci., 2000, 229(1), 230-236.

4. Bailey S E, Olin T J, Bricka R M and Adrian D D, Water Res., 1999, 33(11), 2469-2479.

5. Hasan S, Krishnaiah A, Ghosh T K, Viswanath D S, Boddu V M and Smith E D, Ind Eng Chem Res., 2006, 45, 5066-5077.

6. Navarro R, Guzman J, Saucedo I, Revilla J and Guibal E, Macromol Biosci., 2003, 3, 552-561.

7. Llorens J, Pujola M and Sabate J, J Membr Sci., 2004, 239, 173-181.

8. Nomanbhay S M and Palanisamy K, Electronic J Biotechnol., 2005, 8(1), 43-53.

9. $\quad$ Liang C Y and Marchessault R H, J Polym Sci., 1959, 39(135), 269-278.

10. Xu Y, Ren X and Milford A, J Appl Polym Sci., 2006, 99(4), 1684-1691.

12. Alemdar A, Oztekin N, Erim B F, Ece I O and Gungor N, Bull Mater Sci., 2005, 28(3), 287-291.

13. Ebru Gunister, Dilay Pestreli, Cuneyt H Unlu, Oya Atıc1 and Nurfer Gungor, Carbohyd Polym., 2007, 67(3), 358-365.

14. Ritthidej G C, Phaechamud T and Koizumi T, Int J Pharm., 2002, 232, 11-22.

15. Mucha M and Pawlak A, Thermochimica Acta, 2005, 427, 69-76.

16. Khutoryanskiy V V, Cascone M G, Lazzeri L, Nurkeeva Z S, Mun G A and Mangazbaeva R A, Polymer International, 2002, 52(1), 62-67.

17. Cervera F M, Heinamaki J, Rasanen E, Antikainen O, Nieto O M, Iraizoz Colarte A and Yliruusi J, Int J Pharm., 2004, 281(1), 119-127.

18. Ratto J A, Chen C C and Blumstein R B J, Appl Polym Sci., 1996, 59, 1451-1461.

19. Kuo P C, Sahu D and Yu H H, Polym Degrad Stabil., 2006, 91, 3097-3102.

20. Prakash N, Sudha P N and Renganathan N G, Environ Sci Pollut Res Int., 2011 19(7), 2930-2941, DOI:10.1007/s11356-012-0801-8. 